\title{
Plano Nutricional com Diferentes Níveis de Proteína Bruta e Energia Metabolizável na Ração, para Frangos de Corte
}

\author{
Nadja Susana Mogyca Leandro ${ }^{1}$, Marcos Barcelos Café2, José Henrique Stringhini², \\ Roberto Moraes Filho ${ }^{3}$, Keily Alves de Moura ${ }^{4}$, Renato Pinto da Silva Júnior ${ }^{5}$
}

\begin{abstract}
RESUMO - Dois experimentos foram conduzidos com o objetivo de avaliar quatro planos nutricionais com diferentes níveis de energia (EM) e proteína (PB), denominados PN1 (maior nível de EM e PB), PN2 (médio), PN3 (baixo) e PN4 (menor) nas rações inicial, crescimento e final, sobre o desempenho, o rendimento de carcaça e cortes e a viabilidade econômica na criação de frangos machos (Experimento 1) e fêmeas (Experimento 2). O delineamento experimental adotado foi o de blocos casualizados, com quatro tratamentos e quatro repetições, de 55 aves cada. Foi aplicado o teste Tukey (5\%) para comparação das médias. Os resultados demonstraram que o aumento dos níveis de energia e proteína melhorou o desempenho produtivo dos frangos machos, no período de 1 a 39 dias de idade, e fêmeas, no período de 1 a 46 dias. Os planos nutricionais não afetaram o rendimento de carcaça dos frangos machos. Entretanto, as aves machos alimentadas com rações de mais altos teores de proteína e energia (PN1 e PN2) apresentaram maior rendimento de peito. Não houve diferença significativa entre os tratamentos para os rendimentos de carcaça e cortes de aves fêmeas. O maior retorno econômico em peso vivo de aves machos foi obtido com o plano nutricional de baixa concentração de proteína e energia (PN3). Entretanto, para rendimento de carcaça e corte de aves machos, o melhor retorno econômico foi observado para o PN2. Independentemente do produto comercializado, as aves fêmeas apresentaram melhor econômico sempre se que utilizou o PN3.
\end{abstract}

Palavras-chave: desempenho, frango de corte, programa alimentar, rendimento, viabilidade econômica

\section{Feeding Program with Different Dietary Crude Protein and Metabolizable Energy Levels, forBroilers}

\begin{abstract}
Two trials were conducted to evaluate four different nutritional plans with different energy (ME) and protein (CP) levels, nominated PN1 (highest levels), PN2 (medium), PN3 (low) and PN4 (lowest) in starter, grower and finisher periods of broiler raising. The performance, carcass and parts yield and economic analyses were evaluated in male (Trail 1) and female (Trail 2) broilers. The experimental design consisted of 4 treatments and 4 replicates with 880 chickens, randomized into 16 floor pens (55 birds/pen). When necessary, we used Tukey's test to compared difference among means. The results showed that the increase of nutrients of diets improved the performance of 1-39-day-old male broilers and 1-46-day-old females. The different nutritional plan did not affect the carcass yield of male and female birds. Nevertheless, broilers fed with high protein and energy levels (PN1 and PN2) showed better breast yield. No significant differences among treatments were observed for carcass and part yields. The greatest economic return in kg of weight male broilers was obtained when low protein and energy was used. However, for carcass and part yields of male broilers, PN2 group presented the greatest economic return. Independently of the product sold, female broiler fed PN3 showed better economic return.
\end{abstract}

Key Words: broiler, carcass yield, feeding program, performance

\section{Introdução}

A alimentação constitui um dos fatores de maior relevância na exploração avícola, pois uma dieta adequada pode promover melhoria tanto na produtividade quanto no rendimento de carcaça. As decisões mais importantes que podem ser tomadas na formulação de uma dieta de frangos de corte são relativas às concentrações de proteína e de energia, cujos níveis influenciam tanto o custo da dieta como o desempenho dos frangos de corte.

Trabalhos têm sido publicados mostrando a influência da energia da dieta sobre o desempenho produtivo de frangos de corte. Acréscimo significativo no ganho de peso em frangos de corte alimentados com rações ricas em energia metabolizável (Barbosa \&

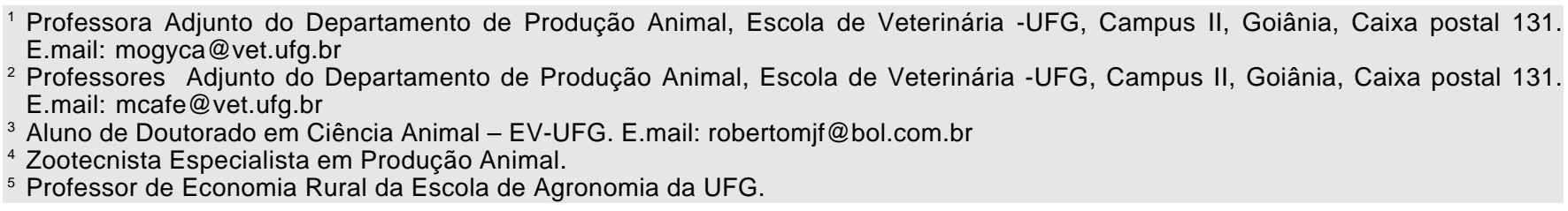


Campos, 1994; Bernal \& Baião, 1996) e melhora na conversão alimentar (Leeson et al., 1996, Nascimento et al.,1998). Com respeito ao consumo de ração, Waldroup (1996) verificou que o aumento da energia metabolizável da dieta não diminui o consumo na mesma proporção, ocorrendo um aumento na ingestão de energia, sugerindo que as linhagens modernas são selecionadas em função da capacidade física do trato gastrointestinal. Entretanto, ajustes da densidade nutricional das rações podem se constituir em uma alternativa para permitir o atendimento das necessidades nutricionais das aves e também para minimizar alguns dos problemas decorrentes da redução de consumo das aves, como ocorre em condições de climas quentes (Junqueira, 1999).

Do mesmo modo, o ajuste dos níveis de proteína pode trazer ganhos produtivos e econômicos importantes, obtidos com a melhoria do desempenho e da qualidade de carcaça de frangos (Silva et al.,1997). A composição corporal dos frangos é afetada tanto pela quantidade como a qualidade da proteína da ração, demonstrando que o aminoácido em menor proporção, comparado à exigência, denomina-se primeiro limitante e restringe o valor da proteína (Castro et al., 1998). A composição de proteínas e aminoácidos da dieta também pode influenciar a deposição de proteína da carcaça, afetando principalmente o rendimento de carne de peito (Kidd et al., 1998).

A redução na deposição de gordura na carcaça está vinculada com ingestão adequada de energia à necessidade para a manutenção e crescimento (Summers \& Leeson, 1984). Nesse contexto, Bernal \& Baião (1996) observaram efeito da elevada densidade calórica da ração inicial sobre a deposição de gordura abdominal do frango de corte abatido. Para Leeson (1995), a composição da carcaça é influenciada mais facilmente pelo balanço de energia:proteína (EM:PB) da dieta. Quando essa relação EM:PB aumenta ocorre uma redução no rendimento de carne, tanto em machos como em fêmeas, assim como, em rações com conteúdo protéico crescente proporcionam maior ingestão protéica e rendimento de carne mais elevado.

Nascimento et al. (1998), avaliando a relação EM: PB na fase inicial de frangos de corte, concluíram que relações altas $(151,5)$ ou baixas $(125)$ podem prejudicar o desempenho das aves e aumentar a gordura na carcaça. Por outro lado, à medida que se aumenta a densidade de nutrientes na ração pode se obter melhora no desempenho zootécnico, mas isso pode não significar melhora no resultado econômico das empresas, avícolas, que buscam produzir um produto economicamente o mais competitivo possível.

O trabalho foi conduzido com o objetivo de avaliar os diferentes programas alimentares, testando níveis de proteína e energia metabolizável, na fase inicial ( 8 a 22 dias), crescimento ( 22 a 39 dias) e final ( 40 a 46 dias) sobre o desempenho, rendimento de carcaça e de cortes e sua viabilidade econômica, para frangos de corte, machos e fêmeas.

\section{Material e Métodos}

Foram conduzidos dois trabalhos simultaneamente, no aviário experimental da Empresa Super Frango, localizada em Itaberaí, Goiás.

Foram utilizados dois galpões experimentais de alvenaria, com dimensões de $24 \mathrm{~m}$ de comprimento por $6,65 \mathrm{~m}$ de largura, divididos em 16 boxes cada $(2,10 \times 2,50 \mathrm{~m})$. Foram alojadas 1.760 aves $(50 \%$ macho e $50 \%$ fêmea) da linhagem Ross 308, com densidade de 10,4 aves $/ \mathrm{m}^{2}$.

Cada grupo de quatro boxes recebeu uma campânula a gás e cada boxe foi equipado com dois bebedouros (um infantil e o outro pendular) e dois comedouros (tubular infantil e tubular adulto) e após 15 dias de idade permaneceu apenas os equipamentos para aves adultas. O material utilizado como cama foi a casca de arroz. O programa de luz era de 23 horas de luz e uma hora de escuro, durante todo o período de criação.

As aves foram pesadas no $1^{\circ}$ e $7^{\circ}$ dia de vida e a seguir no final de cada fase de criação (inicial, crescimento e final). Para ambos experimentos, foram adotados quatro períodos de criação, de acordo com a idade das aves, sendo considerada a fase préinicial (1 a 7 dias), inicial (8 a 21 dias), crescimento (22 a 38 dias) e final (39 a 46 dias). Todas as rações eram fareladas, fornecidas à vontade e medido o consumo por boxe.

Foram testados quatro planos nutricionais para machos (experimento 1) e fêmeas (experimento 2), variando os níveis de proteína (PB) e da energia metabolizável (EM) da ração, caracterizando os planos nutricionais por PN1 (maior nível de EM e PB), PN2 (médio), PN3 (baixo) e PN4 (menor), conforme apresentado na Tabela 1.

A temperatura ambiente foi registrada no período da manhã, utilizando-se um termômetro de máxima e mínima, durante todo período experimental. 
Tabela 1 - Níveis de proteína bruta (\%) e energia metabolizável (kcal/kg de ração) dos planos nutricionais, testados durante as diferentes fases de criação

Table 1 - Levels of crude protein (\%) and metabolizable energy (kcal/kg of diet) of female and male broilers, during different rearing phases

\begin{tabular}{|c|c|c|c|c|c|c|c|}
\hline \multirow{2}{*}{$\begin{array}{l}\text { Plano nutricional } \\
\text { Nutritional plan } \\
\text { Exp. } 1 \\
\text { Trial } 1\end{array}$} & \multirow{2}{*}{$\begin{array}{c}\text { Sexo } \\
\text { Sex } \\
\text { (8 a 21d) } \\
\text { Macho } \\
\text { Male }\end{array}$} & \multicolumn{2}{|c|}{$\begin{array}{c}\text { Ração inicial } \\
\text { Initial } \\
\text { (22 a 38d) }\end{array}$} & \multicolumn{2}{|c|}{$\begin{array}{l}\text { Crescimento } \\
\text { Growth } \\
\text { (39 a 46d) }\end{array}$} & \multicolumn{2}{|c|}{$\begin{array}{l}\text { Final } \\
\text { Final }\end{array}$} \\
\hline & & ${ }^{1} \mathrm{~PB}$ & $\mathrm{EM}^{2}$ & PB & EM & PB & $\overline{\mathrm{EM}}$ \\
\hline$\overline{\mathrm{PN} 1(N P 1)}$ & & 21,50 & 3080 & 20,00 & 3200 & 18,50 & 3300 \\
\hline PN2 (NP2) & & 21,00 & 3050 & 19,17 & 3180 & 17,77 & 3220 \\
\hline PN3 (PN3) & & 20,50 & 3020 & 18,74 & 3130 & 16,95 & 3170 \\
\hline PN4 (PN4) & & 20,45 & 2990 & 18,50 & 3100 & 16,68 & 3150 \\
\hline Exp. 2 & Fêmea & & & & & & \\
\hline Trial 2 & Female & & & & & & \\
\hline PN1 $(N P 1)$ & & 21,50 & 3080 & 19,35 & 3150 & 17,25 & 3230 \\
\hline PN2 (NP2) & & 21,00 & 3050 & 18,50 & 3130 & 16,90 & 3170 \\
\hline PN3 (PN3) & & 20,50 & 3020 & 18,00 & 3080 & 16,40 & 3120 \\
\hline PN4 (PN4) & & 20,45 & 2990 & 18,00 & 3050 & 16,26 & 3100 \\
\hline
\end{tabular}

1 Percentagem de proteína bruta nas rações(Dietary crude protein, \%).

$2 \mathrm{kcal}$ de energia metabolizável/kg na ração (Metabolizable energy, EM/kg).

As composições calculadas das rações estão apresentadas na Tabela 2 e 3, e essas foram formuladas à base de milho, farelo de soja e soja integral tostada para todas as rações da fase pré-inicial e inicial, e também foram utilizados gérmen de milho desengordurado e farinha de carne e ossos, nas fases de crescimento e final. A mesma ração pré-inicial foi oferecida para todos os tratamentos até o sétimo dia de idade e os planos nutricionais, da ração inicial, foi os mesmos para machos e fêmeas.
Nas Tabelas 2 e 3, estão apresentadas as composições calculadas das rações, formuladas à base de milho, farelo de soja e soja integral tostada para todas as rações da fase pré-inicial e inicial; também foram utilizados gérmen de milho desengordurado e farinha de carne e ossos, nas fases de crescimento e final. A mesma ração pré-inicial foi oferecida para todos os tratamentos até o sétimo dia de idade e os planos nutricionais, da ração inicial, foi os mesmos para machos e fêmeas.

Tabela 2 - Composição calculada das rações, dos diferentes planos nutricionais, para machos e fêmeas na fase préinicial e inicial

Table 2 - Calculated composition of the diets in each feeding program for broilers at in the pre starter and initial phases

\begin{tabular}{|c|c|c|c|c|c|}
\hline \multirow[b]{2}{*}{$\begin{array}{l}\text { Composição } \\
\text { Composition }\end{array}$} & \multirow[t]{2}{*}{$\begin{array}{l}\text { Pré-inicia } \\
\text { Pré starter }\end{array}$} & \multicolumn{4}{|c|}{$\begin{array}{r}\text { Inicial } \\
\text { Initial } \\
\end{array}$} \\
\hline & & $\begin{array}{l}\text { PN1 } \\
N P 1\end{array}$ & $\begin{array}{l}\mathrm{PN} 2 \\
N P 2\end{array}$ & $\begin{array}{l}\mathrm{PN} 3 \\
N P 3\end{array}$ & $\begin{array}{l}\text { PN4 } \\
\text { NP4 }\end{array}$ \\
\hline $\begin{array}{l}\text { Proteína bruta (\%) } \\
\text { Crude protein }\end{array}$ & 23,02 & 20,45 & 20,50 & 21,00 & 21,50 \\
\hline $\begin{array}{l}\text { Energia metabolizável ( } \mathrm{kcal} / \mathrm{kg}) \\
\text { Metabolizable energy }\end{array}$ & 2920 & 2990 & 3020 & 3050 & 3080 \\
\hline $\begin{array}{l}\text { Cálcio (\%) } \\
\text { Calcium }\end{array}$ & 0,95 & 1,19 & 0,95 & 0,95 & 0,95 \\
\hline $\begin{array}{l}\text { Fósforo disponível (\%) } \\
\text { Available phosphorus }\end{array}$ & 0,45 & 0,44 & 0,44 & 0,44 & 0,44 \\
\hline $\begin{array}{l}\text { Metionina (\%) } \\
\text { Methionine }\end{array}$ & 0,57 & 0,52 & 0,53 & 0,55 & 0,56 \\
\hline $\begin{array}{l}\text { Metionina + Cistina }(\%) \\
\text { Met }+ \text { Cys }\end{array}$ & 0,94 & 0,85 & 1,05 & 1,10 & 1,15 \\
\hline $\begin{array}{l}\text { Lisina }(\%) \\
\text { Lysine }\end{array}$ & 1,30 & 1,14 & 1,16 & 1,21 & 1,24 \\
\hline
\end{tabular}


Tabela 3 - Composição calculada das rações experimentais, para machos e fêmeas na fase de crescimento e final Table 3 - Calculated composition of the experimental diets in each nutritional plan for broilers at the growing and final phases

\begin{tabular}{|c|c|c|c|c|c|c|c|c|}
\hline $\begin{array}{l}\text { Composição } \\
\text { Composition }\end{array}$ & \multicolumn{4}{|c|}{$\begin{array}{l}\text { Machos } \\
\text { Males }\end{array}$} & \multicolumn{4}{|c|}{$\begin{array}{l}\text { Fêmeas } \\
\text { Females }\end{array}$} \\
\hline $\begin{array}{l}\text { Ração de crescimento } \\
\text { Growing diet }\end{array}$ & $\begin{array}{l}\text { PN1 } \\
N P 1\end{array}$ & $\begin{array}{l}\mathrm{PN} 2 \\
N P 2\end{array}$ & $\begin{array}{l}\text { PN3 } \\
\text { NP3 }\end{array}$ & $\begin{array}{l}\text { PN4 } \\
\text { NP4 }\end{array}$ & $\begin{array}{l}\text { PN1 } \\
N P 1\end{array}$ & $\begin{array}{l}\mathrm{PN} 2 \\
N P 2\end{array}$ & $\begin{array}{l}\text { PN3 } \\
N P 3\end{array}$ & $\begin{array}{l}\text { PN4 } \\
\text { NP4 }\end{array}$ \\
\hline $\begin{array}{l}\text { Proteína bruta }(\%) \\
\text { Crude protein }\end{array}$ & 20,00 & 19,17 & 18,74 & 18,50 & 19,35 & 18,50 & 18,00 & 18,00 \\
\hline $\begin{array}{l}\text { Energia metabolizável }(\mathrm{kcal} / \mathrm{kg}) \\
\text { Metabolizable energy }\end{array}$ & 3200 & 3180 & 3130 & 3100 & 3150 & 3130 & 3080 & 3050 \\
\hline $\begin{array}{l}\text { Cálcio }(\%) \\
\text { Calcium }\end{array}$ & 0,93 & 0,93 & 0,93 & 0,93 & 0,93 & 0,93 & 0,93 & 0,95 \\
\hline $\begin{array}{l}\text { Fósforo disp. }(\%) \\
\text { Available phosphorus }\end{array}$ & 0,43 & 0,43 & 0,43 & 0,43 & 0,43 & 0,43 & 0,43 & 0,43 \\
\hline $\begin{array}{l}\text { Metionina (\%) } \\
\text { Methionine }\end{array}$ & 0,55 & 0,53 & 0,51 & 0,50 & 0,46 & 0,43 & 0,41 & 0,41 \\
\hline Metionina + Cistina (\%) & 0,87 & 0,84 & 0,81 & 0,80 & 0,77 & 0,90 & 0,71 & 0,70 \\
\hline $\begin{array}{l}\text { Met }+C y s \\
\text { Lisina (\%) } \\
\text { Lysine }\end{array}$ & 1,16 & 1,12 & 1,08 & 1,07 & 1,06 & 1,00 & 0,94 & 0,92 \\
\hline & \multicolumn{4}{|c|}{$\begin{array}{l}\text { Machos } \\
\text { Males }\end{array}$} & \multicolumn{4}{|c|}{$\begin{array}{l}\text { Fêmeas } \\
\text { Females } \\
\end{array}$} \\
\hline & $\begin{array}{l}\text { PN1 } \\
N P 1\end{array}$ & $\begin{array}{l}\mathrm{PN} 2 \\
N P 2\end{array}$ & $\begin{array}{l}\mathrm{PN} 3 \\
N P 3\end{array}$ & $\begin{array}{l}\mathrm{PN} 4 \\
\text { NP4 }\end{array}$ & $\begin{array}{l}\text { PN1 } \\
N P 1\end{array}$ & $\begin{array}{l}\mathrm{PN} 2 \\
N P 2\end{array}$ & $\begin{array}{l}\mathrm{PN} 3 \\
N P 3\end{array}$ & $\begin{array}{l}\mathrm{PN} 4 \\
\text { NP4 }\end{array}$ \\
\hline $\begin{array}{l}\text { Proteína bruta (\%) } \\
\text { Crude protein }\end{array}$ & 18,50 & 17,77 & 16,95 & 16,68 & 17,25 & 16,90 & 16,40 & 16,26 \\
\hline $\begin{array}{l}\text { Energia metabolizável }(\mathrm{kcal} / \mathrm{kg}) \\
\text { Metabolizable energy }\end{array}$ & 3300 & 3220 & 3170 & 3150 & 3230 & 3170 & 3120 & 3100 \\
\hline Cálcio (\%) & 0,88 & 0,88 & 0,88 & 0,90 & 0,88 & 0,86 & 0,88 & 0,90 \\
\hline $\begin{array}{l}\text { Fósforo disponível (\%) } \\
\text { Available phosphorus }\end{array}$ & 0,38 & 0,38 & 0,38 & 0,38 & 0,38 & 0,38 & 0,38 & 0,38 \\
\hline $\begin{array}{l}\text { Metionina (\%) } \\
\text { Methionine }\end{array}$ & 0,50 & 0,47 & 0,46 & 0,45 & 0,40 & 0,38 & 0,35 & 0,34 \\
\hline $\begin{array}{l}\text { Metionina + Cistina (\%) } \\
\text { Met + Cys }\end{array}$ & 0,80 & 0,76 & 0,73 & 0,72 & 0,69 & 0,66 & 0,63 & 0,73 \\
\hline $\begin{array}{l}\text { Lisina (\%) } \\
\text { Lysine }\end{array}$ & 1,06 & 1,00 & 0,97 & 0,95 & 0,93 & 0,91 & 0,82 & 0,80 \\
\hline
\end{tabular}

As variáveis de desempenho estudadas foram o consumo de ração, ganho de peso, conversão alimentar e o peso ao abate. Para a análise de rendimento de carcaça, quando os frangos atingiram 46 dias de idade, foram retiradas ao acaso cinco aves por boxe, 20 aves por tratamento, com um total de 80 aves avaliadas (para cada experimento). Após serem submetidas a um período de jejum de seis horas, foram transportadas para o abatedouro. Na plataforma, as mesmas foram pesadas individualmente e em seguida abatidas, evisceradas e pesadas em balança de precisão de um grama.

A carcaça foi resfriada no túnel de congelamento a $-20^{\circ} \mathrm{C}$ durante uma hora, sem passar pelo "chiller". Os cortes foram então realizados e pesados: peito, pernas (coxa com sobrecoxa), asas, dorso, pés, cabeça e pescoço, em balança eletrônica com precisão 1,0 g.

Para cálculo de rendimento de carcaça, tomou-se como base o peso vivo e o peso eviscerado, obtidos por pesagem da carcaça com cabeça, pescoço e pé. Os rendimentos de peito, pernas, asas, cabeça, pescoço, pés e o dorso foram determinados pela razão entre o peso do corte e o peso da carcaça eviscerada. A gordura da carcaça retirada do abdômen e da moela foi pesada, determinando-se a sua percentagem em relação ao peso da carcaça eviscerada.

O delineamento estatístico adotado, para ambos experimentos, foi em blocos casualizados para quatro tratamentos (planos nutricionais) com quatro repetições e 55 aves por unidade experimental. O experimento foi realizado em dois galpões experimentais, sendo cada galpão considerado um bloco. As análises 
estatísticas foram realizadas pelo do procedimento Análise para Modelos Lineares do SAEG - (UNIVERSIDADE FEDERAL DE VIÇOSA - UFV, 1997). As médias dos tratamentos foram comparadas pelo teste de Tukey a $5 \%$ de probabilidade.

Para o estudo de viabilidade econômica foram considerados o consumo e os custos das rações e o preço dos produtos no mercado (peso vivo do frango, da carcaça eviscerada com cabeça, pé e pescoço e dos diferentes cortes). Todos os demais custos operacionais foram considerados iguais para todos os tratamentos.

\section{Resultados e Discussão}

As médias registradas de temperatura ambiente, durante o período experimental, foram à máxima de 31,1 e mínima de $18,3{ }^{\circ} \mathrm{C}$, dentro do galpão.

$\mathrm{Na}$ Tabela 4, estão apresentados os resultados de desempenho dos machos (Experimento1). Pode-se observar que não houve diferença significativa no consumo de ração em todos os períodos estudados, mas os resultados de conversão alimentar e ganho de peso para o período 1 a 39 dias de idade, apresenta- ram-se melhores em aves alimentadas com o maior plano nutricional (PN1) quando comparadas com aquelas submetidas ao menor plano $(\mathrm{PN} 4)(\mathrm{P}<0,05)$.

Não se observou efeito $(\mathrm{P}>0,05)$ dos planos nutricionais sobre o desempenho das fêmeas na fase inicial (Tabela 5). Já nos períodos de 1 a 39 dias e no período total de criação (1-46 dias de idade), os valores mostraram-se diferentes $(\mathrm{P}<0,05)$, onde o ganho de peso obtido para o maior plano nutricional (PN1) foi superior ao de baixa plano $(\mathrm{PN} 3)(\mathrm{P}<0,05)$, porém não diferiu estatisticamente dos planos PN2 e PN4, para ambos os períodos. A conversão alimentar mostrou-se afetada pelos planos nutricionais somente no período total, em que o plano PN4 apresentou pior conversão alimentar em relação ao PN2, mas não diferiu dos outros tratamentos.

Na Tabela 6, estão apresentados os dados referentes ao índice de eficiência produtiva (IEP) e consumo de nutrientes, para machos e fêmeas. Os diferentes tratamentos não influenciaram o IEP, para o período total de criação (1 a 46 dias), embora os planos PN2 e PN1 obtiveram numericamente melhores índices produtivos, em machos e fêmeas. Com o

Tabela 4 - Desempenho de machos de frangos de corte submetidos a diferentes planos nutricionais (Exp. 1) Table 4 - Performance of broiler males according to the different feeding programs (trial 1)

\begin{tabular}{|c|c|c|c|c|}
\hline \multirow[b]{2}{*}{$\begin{array}{l}\text { Plano nutricional } \\
\text { Feeding program }\end{array}$} & \multicolumn{4}{|c|}{$\begin{array}{c}\text { Fases de criação (dias) } \\
\text { Periods (days) }\end{array}$} \\
\hline & 1 a 7 & 1 a 21 & 1 a 39 & 1 a 46 \\
\hline & \multicolumn{4}{|c|}{$\begin{array}{c}\text { Consumo de ração, } \mathrm{g} \\
\text { Feed intake }\end{array}$} \\
\hline PN1 (NP 1) & 141,70 & 1147 & 3.654 & $4.869,14$ \\
\hline PN2 (NP 2) & 145,70 & 1120 & 3.658 & $4.830,33$ \\
\hline PN3 (NP 3) & 142,90 & 1139 & 3.645 & $4.838,77$ \\
\hline PN4 (NP 4) & 146,30 & 1158 & 3.667 & $4.831,75$ \\
\hline \multirow[t]{2}{*}{$\mathrm{CV}(\%)$} & 5,87 & 3,41 & 2,25 & 2,30 \\
\hline & \multicolumn{4}{|c|}{$\begin{array}{c}\text { Ganho de Peso, g } \\
\text { Weight gain }\end{array}$} \\
\hline PN1 (NP 1) & 99,0 & 691 & $2.167 \mathrm{a}$ & $2.766,03$ \\
\hline PN2 (NP 2) & 103,3 & 692 & $2.136 \mathrm{ab}$ & $2.686,77$ \\
\hline PN3 (NP 3) & 100,8 & 672 & $2.070 \mathrm{ab}$ & $2.563,10$ \\
\hline PN4 (NP 4) & 103,7 & 663 & $1.976 \mathrm{~b}$ & $2.606,62$ \\
\hline \multirow[t]{2}{*}{$\mathrm{CV}(\%)$} & 8,05 & 2,61 & 3,76 & 4,95 \\
\hline & \multicolumn{4}{|c|}{$\begin{array}{c}\text { Conversão Alimentar } \\
\text { Feed : gain ratio }\end{array}$} \\
\hline PN1 (NP 1) & 1,53 & 1,66 & $1,69 b$ & 1,76 \\
\hline PN2 (NP 2) & 1,46 & 1,62 & $1,71 \mathrm{ab}$ & 1,80 \\
\hline PN3 (NP 3) & 1,53 & 1,69 & $1,76 \mathrm{ab}$ & 1,89 \\
\hline PN4 (NP 4) & 1,44 & 1,74 & $1,86 \mathrm{a}$ & 1,86 \\
\hline $\mathrm{CV}(\%)$ & 10,3 & 4,42 & 4,07 & 4,30 \\
\hline
\end{tabular}

Médias, seguidas de letras diferentes, diferem $(P<0,05)$ pelo teste Tukey.

Means followed by different letters within the same column differ $(P<.05)$ by Tukey test. 
aumento do plano nutricional das dietas, houve acréscimo na ingestão de energia metabolizável para machos $(\mathrm{P}<0,05)$ e de proteína para fêmeas $(\mathrm{P}<0,05)$. Da mesma forma, ambos os sexos apresentaram maior $(\mathrm{P}<0,05)$ ingestão de metionina e de lisina. $\mathrm{O}$ aumento no plano nutricional não influenciou a mortalidade (\%) nos frangos de cortes, machos ou fêmeas. As médias das mortalidades para os planos PN1, PN2, PN3 e PN4 foram 4,5, 2,2, 3,1 e 2,3 (machos) e 3,4, 5,9, 4,5 e 5,45 (fêmeas), respectivamente.

Com o aumento do plano nutricional, os machos apresentaram melhoras no ganho de peso e na conversão alimentar, até o período de 39 dias de idade. No entanto, no período total (até 46 dias de idade) esse efeito não foi observado, sugerindo que os machos tiveram um ganho compensatório no período final de criação (40-46 dias de idade). Isso pode indicar que machos abatidos mais tardiamente e alimentados com planos nutricionais com pequenas variações nos níveis de energia e proteína não apresentam ganhos significativos no peso final. Esses dados concordam com os observados por Lana et al. (2001), que obtiveram melhora no ganho de peso de frango de corte com aumento no plano nutricional da dieta, até a fase de crescimento, mas após esse período não houve efeito significativo entre os dois planos nutricionais estudados. Entretanto, as fêmeas não apresentaram esse mesmo comportamento, visto que os planos nutricionais influenciaram o ganho de peso e conversão alimentar para o período de 1 a 39 e 1 a 46 dias de idade.

Considerando a fase total de criação, para ambos os sexos, os dados de desempenho, embora estatisticamente não diferentes $(\mathrm{P}>0,05)$, numericamente demonstram que o tratamento PN3 apresentou o pior ganho de peso e conversão alimentar do que os tratamentos PN1, PN2 e PN4. Esse resultado, contraditório, pode estar relacionado com o fato da ração inicial do programa PN3 ter a relação energia:proteína mais alta $(147,3)$ do que todos os outros tratamentos (146; 145,2 e 143,3 PN4, PN2 e PN1, respectivamente), para machos e também para as fêmeas $(146,2$; 147,$3 ; 145,2$ e 143,3 para as dietas com PN4, PN3, $\mathrm{PN} 2$ e PN1, respectivamente). Com isso, pode-se inferir que a relação EM:PB da ração inicial (8 a 22 dias de idade) tem efeito importante no desempenho

Tabela 5 - Desempenho de fêmeas de frangos de corte submetidas a diferentes planos nutricionais (Exp.2) Table 5 - Performance of broiler females according to raising periods, submitted to different nutritional plan (trial 2)

Fases de criação (dias)

Periods (days)

Plano nutricional

1 a 7

1 a 21

1 a 39

1 a 46

Feeding program

\begin{tabular}{|c|c|c|c|c|}
\hline \multirow[b]{2}{*}{ PN1 (NP 1) } & \multicolumn{4}{|c|}{$\begin{array}{c}\text { Consumo de ração, } \mathrm{g} \\
\text { Feed intake }\end{array}$} \\
\hline & 146 & 1.096 & 3.386 & 4.348 \\
\hline PN2 (NP 2) & 143 & 1.096 & 3.310 & 4.404 \\
\hline PN3 (NP 3) & 153 & 1.052 & 3.243 & 4.376 \\
\hline PN4 (NP 4) & 146 & 1.072 & 3.264 & 4.348 \\
\hline \multirow[t]{2}{*}{ CV (\%) } & 4,48 & 2,62 & 2,25 & 2,55 \\
\hline & \multicolumn{4}{|c|}{$\begin{array}{c}\text { Ganho de peso, } \mathrm{g} \\
\text { Weight gain }\end{array}$} \\
\hline $\mathrm{PN} 1(N P 1)$ & 103 & 646 & $1817 \mathrm{a}$ & $2203 a$ \\
\hline PN2 (NP 2) & 101 & 636 & $1750 \mathrm{ab}$ & $2177 \mathrm{ab}$ \\
\hline PN3 (NP 3) & 111 & 613 & $1690 \mathrm{~b}$ & $2057 \mathrm{~b}$ \\
\hline PN4 (NP 4) & 103 & 620 & $1734 \mathrm{ab}$ & $2108 \mathrm{ab}$ \\
\hline \multirow[t]{2}{*}{$\mathrm{CV}(\%)$} & 6,27 & 3,29 & 2,47 & 2,57 \\
\hline & \multicolumn{4}{|c|}{$\begin{array}{l}\text { Conversão alimentar } \\
\text { Feed:gain ratio }\end{array}$} \\
\hline $\mathrm{PN} 1\left(\begin{array}{lll}N P & 1\end{array}\right)$ & 1,47 & 1,70 & 1,86 & $2,05 \mathrm{ab}$ \\
\hline PN2 ( $\left(\begin{array}{ll}N P & 2\end{array}\right)$ & 1,46 & 1,72 & 1,89 & $2,02 b$ \\
\hline PN3 (NP 3) & 1,36 & 1,72 & 1,91 & $2,13 \mathrm{a}$ \\
\hline PN4 (NP 4) & 1,39 & 1,73 & 1,88 & $2,06 \mathrm{ab}$ \\
\hline CV $(\%)$ & 14,7 & 3,60 & 2,67 & 1,79 \\
\hline
\end{tabular}

Médias, seguidas de letras diferentes, diferem $(P<0,05)$ pelo teste Tukey.

Means followed by different letters within the same column differ $(P<.05)$ by Tukey test.

R. Bras. Zootec., v.32, n.3, p.620-631, 2003 
Tabela 6 - Índice de eficiência produtiva (IEP) e consumo de nutrientes para fêmeas e machos de frangos de corte submetidos a diferentes planos nutricionais

Table 6 - Index of productive efficiency IEP) and nutrient intake for broiler females and males submitted to different nutritional plan

\begin{tabular}{|c|c|c|c|c|}
\hline \multirow{3}{*}{$\begin{array}{l}\text { Variáveis } \\
\text { Variable }\end{array}$} & \multicolumn{4}{|c|}{$\begin{array}{l}\text { Plano nutricional } \\
\text { Feeding program }\end{array}$} \\
\hline & PN1 & PN2 & PN3 & PN4 \\
\hline & $P N 1$ & $P N 2$ & $P N 3$ & $\mathrm{P} N 4$ \\
\hline \multicolumn{5}{|l|}{$\begin{array}{l}\text { Experimento com machos } \\
\text { Male trial }\end{array}$} \\
\hline $\begin{array}{l}\text { IEP } \\
\text { Consumo de nutrientes }\end{array}$ & 331 & 325 & 293 & 309 \\
\hline $\begin{array}{l}\text { Nutrient intake } \\
\text { Proteína (g/ave) } \\
\text { Crude protein }(\mathrm{g} / \mathrm{bird})\end{array}$ & $974^{\mathrm{b}}$ & $932^{\mathrm{ab}}$ & $908^{a b}$ & $898^{a}$ \\
\hline $\begin{array}{l}\mathrm{EM}(\mathrm{kcal} / \mathrm{ave}) \\
\text { EM (kcal/chick) }\end{array}$ & 15.549 & 15.245 & 15.057 & 14.901 \\
\hline $\begin{array}{l}\text { Metionina (mg/ave) } \\
\text { Methionine (mg/bird) }\end{array}$ & $26,42^{\mathrm{a}}$ & $25,02^{\mathrm{b}}$ & $24,20^{\mathrm{bc}}$ & $23,76^{\mathrm{c}}$ \\
\hline $\begin{array}{l}\text { Lisina (mg/ave) } \\
\text { Lysine (mg/bird) }\end{array}$ & $56,19^{\mathrm{a}}$ & $54,38^{\mathrm{ab}}$ & $51,99^{\mathrm{bc}}$ & $51,32^{\mathrm{c}}$ \\
\hline \multicolumn{5}{|l|}{$\begin{array}{l}\text { Experimento com fêmeas } \\
\text { Female trial }\end{array}$} \\
\hline $\begin{array}{l}\text { IEP } \\
\text { Consumo de nutrientes } \\
\text { Nutrient intake }\end{array}$ & 232 & 227 & 208 & 218 \\
\hline $\begin{array}{l}\text { Proteína (g/ave) } \\
\text { Crude protein (g/bird) }\end{array}$ & 875 & 827 & 799 & 793 \\
\hline $\begin{array}{l}\mathrm{EM}(\mathrm{kcal} / \mathrm{ave}) \\
M E(\text { kcal/bird })\end{array}$ & $14.203^{\mathrm{a}}$ & $13.724^{\mathrm{ab}}$ & $13.446^{\mathrm{ab}}$ & $13.242^{\mathrm{b}}$ \\
\hline $\begin{array}{l}\text { Metionina (mg/ave) } \\
\text { Methionine (mg/bird) }\end{array}$ & $21,20^{\mathrm{a}}$ & $19,67^{b}$ & $18,61^{\mathrm{c}}$ & $18,19^{c}$ \\
\hline $\begin{array}{l}\text { Lisina (mg/ave) } \\
\text { Lysine (mg/bird) }\end{array}$ & $48,49^{\mathrm{a}}$ & $45,37^{\mathrm{b}}$ & $42,23^{\mathrm{c}}$ & $41,31^{\mathrm{c}}$ \\
\hline
\end{tabular}

Médias, seguidas de letras diferentes, dentro da mesma linha diferem $(P<0,05)$ pelo teste Tukey.

Means followed by different letters within the same row differ $(P<.05)$ by Tukey test.

das fêmeas e dos machos (quando abatidos com menos idade). Silva et al. (2001) observaram efeito decrescente sobre o consumo e peso vivo de frangos de corte, machos, aos 42 dias de idade com aumento da relação EM:PB das dietas.

Pode-se observar uma relação direta entre o aumento dos níveis protéicos e energéticos da ração com maior ingestão de nutrientes. Os machos alimentados com plano nutricional PN1 ingeriram maior $(\mathrm{P}<0,05)$ quantidade de proteína, metionina e lisina do que as aves submetidas aos planos PN3 e PN4. No entanto, esse aumento na ingestão não se converteu em maior ganho de peso, já que não houve diferença estatística, o que é considerado uma desvantagem. Esses resultados estão coerentes com aqueles observados por Stringhini (1998), que ao analisar os efeitos de aminoácidos sulfurados, verificou que estes não foram eficientes em determinar diferenças $(\mathrm{P}>0,05)$ para os parâmetros de desempenho. Do mesmo modo, Cella et al.(2001) não observaram diferenças entre diversos planos nutricionais, com relação à exigência de lisina, sobre o desempenho de frango de corte para o período de 1 a 41 e 1 a 49 dias de idade. Anteriormente, Pesti (1999), estudando quatro níveis de proteína na dieta $(17,5 ; 18,6 ; 19,8 ; 20,9$ e $22 \%)$ na fase de crescimento, observou que, à medida que o nível de proteína elevou-se, a taxa de crescimento e a conversão alimentar melhoraram e a deposição de gordura abdominal diminuiu, no entanto as diferenças entre os níveis de proteína estudados no presente trabalho foram menores.

Pode-se observar acréscimo na ingestão de energia metabolizável nas fêmeas $(\mathrm{P}<0,05)$ e nos machos $(\mathrm{P}>0,05)$ com o aumento do plano nutricional das 
rações, concordando com Junqueira et al. (1999), onde relatam que os frangos consomem mais energia quando alimentados com rações de alto valor calórico em relação àqueles que são alimentados com rações de baixa energia.

Na Tabela 7, estão apresentados os dados de rendimento de carcaça e de cortes em relação ao peso eviscerado de frangos machos e fêmeas submetidos a diferentes planos nutricionais. Os rendimentos de carcaça e de cortes não diferiram estatisticamente para os diferentes planos nutricionais, com exceção do rendimento de peito para machos, onde o plano PN1 foi superior $(\mathrm{P}<0,05)$ aos $\mathrm{PN} 4$ e PN3. Os resultados de rendimento de carcaça, dos machos e das fêmeas, discordam daqueles obtidos por Bertechini et al. (1991a), em que o rendimento de carcaça eviscerada foi melhor nas aves alimentadas com níveis de energia metabolizável médio $(3.000 \mathrm{kcal} / \mathrm{kg}$ de EM) e alto (3.200 kcal/kg de EM) em relação ao nível baixo (2.800 kcal/kg), e por Peak et al. (2000), que também observaram uma redução no rendimento de carcaça com a diminuição do plano nutricional (níveis de PB). Por outro lado, Deschepper \& De Groote (1995) constataram que a percentagem de rendimento de carcaça e a proteína da carne não foram afetadas pelo plano nutricional (variação de proteína e aminoácidos).

$\mathrm{O}$ maior rendimento de peito para machos ali- mentados com o plano nutricional PN1, pode estar relacionado com o nível de energia da ração como observado por Bastos et al. (1998) que encontraram melhor rendimento de peito em machos alimentados com rações de $3.116 \mathrm{kcal}$ de EM. Assim como, com a menor relação EM:PB, como observado por Silva et al. (2001), em que planos nutricionais com a relação EM:PB maior apresentaram menores $(\mathrm{P}<0,05)$ pesos de carne de peito e de pernas em machos. No entanto, no presente experimento pode-se observar que o consumo de energia metabolizável para os machos (Tabela 6) não variou entre os tratamentos, mas o consumo de proteína foi crescente, com maior ingestão de proteína para o grupo alimentado com o plano PN1, o que levou a um consumo maior de metionina e de lisina, explicando essa melhora. Kidd et al. (1998) e Cella et al. (2001) verificaram uma maior deposição de carne de peito em frangos de corte submetidos às rações com níveis de lisina acima do recomendado pelo NRC (1994).

A percentagem de gordura abdominal foi menor para os machos alimentados com o plano PN1 $(\mathrm{P}<0,01)$ quando comparado com $\mathrm{PN} 2$, sem diferenças entre os outros planos $(\mathrm{P}>0,05)$ testados. Esses resultados não seguem uma lógica metabólica, pois a relação energia:proteína (143,2; 160,0 e 178,3 para as rações: inicial, crescimento e final, respectivamente) foi menor nas dietas de PN1 quando comparadas com

Tabela 7 - Rendimento de carcaça e cortes de frangos de corte, machos e fêmeas, submetidos a diferentes planos nutricionais

Table 7 - Carcass yield and cut-parts yield of broilers under different feeding program

\begin{tabular}{|c|c|c|c|c|c|c|}
\hline \multirow[b]{2}{*}{$\begin{array}{l}\text { Plano nutricional } \\
\text { Feeding program }\end{array}$} & \multicolumn{6}{|c|}{$\begin{array}{c}\text { Rendimento de carcaça e cortes ( } \% \text { ) } \\
\text { Carcass yield and parts }(\%)\end{array}$} \\
\hline & $\begin{array}{l}\text { Carcaça } \\
\text { Carcass }\end{array}$ & $\begin{array}{c}\text { Pernas } \\
\text { Thigh }+ \text { drumstick }\end{array}$ & $\begin{array}{c}\text { Peito } \\
\text { Breast }\end{array}$ & $\begin{array}{l}\text { A s a } \\
\text { Wing }\end{array}$ & $\begin{array}{l}\text { Dorso } \\
\text { Rack }\end{array}$ & $\begin{array}{c}\text { Gordura } \\
\text { Fat }\end{array}$ \\
\hline \multicolumn{7}{|l|}{ Machos } \\
\hline $\begin{array}{l}\text { PN1 (PN 1) } \\
\text { PN2 (PN 2) } \\
\text { PN3 (PN 3) } \\
\text { PN4 (PN 4) } \\
\text { CV(\%) }\end{array}$ & $\begin{array}{r}79,74 \\
82,64 \\
79,44 \\
80,19 \\
2,13\end{array}$ & $\begin{array}{r}27,49 \\
28,37 \\
28,72 \\
28,44 \\
2,17\end{array}$ & $\begin{array}{l}29,42^{\mathrm{a}} \\
28,17^{\mathrm{ab}} \\
27,49^{\mathrm{b}} \\
26,91^{\mathrm{b}} \\
2,47\end{array}$ & $\begin{array}{r}9,69 \\
10,03 \\
10,29 \\
10,12 \\
2,94\end{array}$ & $\begin{array}{r}16,98 \\
17,10 \\
17,84 \\
18,30 \\
4,50\end{array}$ & $\begin{array}{l}2,38^{\mathrm{b}} \\
2,87^{\mathrm{a}} \\
2,65^{\mathrm{ab}} \\
2,65^{\mathrm{ab}} \\
8,54\end{array}$ \\
\hline \multicolumn{7}{|l|}{$\begin{array}{l}\text { Fêmeas } \\
\text { Female }\end{array}$} \\
\hline $\begin{array}{l}\text { PN1 } 1(P N 1) \\
\text { PN2 ( } P N \text { 2) } \\
\text { PN3 ( } P N 3) \\
\text { PN4 (PN 4) } \\
\text { CV(\%) }\end{array}$ & $\begin{array}{r}76,91 \\
77,42 \\
77,64 \\
75,69 \\
2,97\end{array}$ & $\begin{array}{r}27,19 \\
27,43 \\
26,73 \\
26,44 \\
2,23\end{array}$ & $\begin{array}{r}30,48 \\
28,94 \\
30,38 \\
29,64 \\
3,13\end{array}$ & $\begin{array}{r}9,88 \\
10,46 \\
10,19 \\
10,38 \\
3,54\end{array}$ & $\begin{array}{r}17,78 \\
18,23 \\
18,10 \\
18,26 \\
3,12\end{array}$ & $\begin{array}{l}2,96 \\
3,35 \\
3,10 \\
3,28 \\
7,42\end{array}$ \\
\hline
\end{tabular}

Médias seguidas de letras diferentes diferem $(P<0,05)$ pelo teste Tukey.

Means followed by different letters within the same column differ $(P<.05)$ by Tukey test. 
Tabela 8 - Receita obtida com a comercialização do frango inteiro e em carcaça (com pé, cabeça e pescoço), alimentados com diferentes planos nutricionais

Table 8 - Income obtained with commercialization of cut-parts and carcass of broilers under different feeding program

\begin{tabular}{|c|c|c|c|c|}
\hline & \multicolumn{4}{|c|}{$\begin{array}{l}\text { Plano nutricional } \\
\text { Feeding program }\end{array}$} \\
\hline & $\begin{array}{l}\text { PN1 } \\
P N 1\end{array}$ & $\begin{array}{l}\text { PN2 } \\
P N 2\end{array}$ & $\begin{array}{l}\text { PN3 } \\
P N 3\end{array}$ & $\begin{array}{l}\text { PN4 } \\
\text { PN } 4\end{array}$ \\
\hline \multicolumn{5}{|l|}{$\begin{array}{l}\text { Machos } \\
\text { Males }\end{array}$} \\
\hline $\begin{array}{l}\text { Despesa total com ração }(\mathrm{R} \$)^{1} \\
\text { Feed cost }(R \$)\end{array}$ & 1,318 & 1,247 & 1,206 & 1,182 \\
\hline $\begin{array}{l}\text { Peso vivo }(\mathrm{g}) \\
\text { Live weight }(g)\end{array}$ & 2.701 & 2.627 & 2.633 & 2.558 \\
\hline $\begin{array}{l}\text { Preço do } \mathrm{kg} \text { do peso vivo }(\mathrm{R} \$) \\
\text { Price of live cost }(R \$)\end{array}$ & 0,71 & 0,71 & 0,71 & 0,71 \\
\hline $\begin{array}{l}\text { Custo de ração/kg de } \mathrm{PV}(\mathrm{R} \$) \\
\text { Diet cost/kg } L W(R \$)\end{array}$ & 0,49 & 0,47 & 0,46 & 0,46 \\
\hline $\begin{array}{l}\text { Receita bruta }(\mathrm{R} \$) \\
\text { Total income }(R S)\end{array}$ & 1,92 & 1,87 & 1,87 & 1,82 \\
\hline $\begin{array}{l}\text { Receita líquida }(\mathrm{R} \$)^{2} \\
\text { Net income }(R \$)\end{array}$ & 0,60 & 0,62 & 0,66 & 0,63 \\
\hline $\begin{array}{l}\text { Peso da carcaça eviscerada (g) } \\
\text { Carcass weight }(g)\end{array}$ & 2.162 & 2.166 & 2.093 & 2.051 \\
\hline $\begin{array}{l}\text { Preço do } \mathrm{kg} \text { da carcaça }(\mathrm{R} \$) \\
\text { Carcass price }(R \$ / \mathrm{kg})\end{array}$ & 1,35 & 1,35 & 1,35 & 1,35 \\
\hline $\begin{array}{l}\text { Custo de ração/kg de carcaça }(\mathrm{R} \$) \\
\text { Diet cost/kg carcass }(R \$)\end{array}$ & 0,61 & 0,58 & 0,58 & 0,58 \\
\hline $\begin{array}{l}\text { Receita bruta }(\mathrm{R} \$) \\
\text { Total income }(R S)\end{array}$ & 2,92 & 2,92 & 2,83 & 2,77 \\
\hline $\begin{array}{l}\text { Receita líquida }(\mathrm{R} \$) \\
\text { Net income }(R S)\end{array}$ & 1,60 & 1,68 & 1,62 & 1,59 \\
\hline \multicolumn{5}{|l|}{$\begin{array}{l}\text { Fêmeas } \\
\text { Females }\end{array}$} \\
\hline $\begin{array}{l}\text { Despesa total com ração }(\mathrm{R} \$) \\
\text { Feed cost }(R \$)\end{array}$ & 1,13 & 1,06 & 0,98 & 1,04 \\
\hline $\begin{array}{l}\text { Peso vivo }(\mathrm{g}) \\
\text { Live weight }(g)\end{array}$ & 2.300 & 2.220 & 2.190 & 2.260 \\
\hline $\begin{array}{l}\text { Preço do } \mathrm{kg} \text { do peso vivo }(\mathrm{R} \$) \\
\text { Price of live cost }(R \$)\end{array}$ & 0,71 & 0,71 & 0,71 & 0,71 \\
\hline $\begin{array}{l}\text { Custo de ração/kg de } \mathrm{PV}(\mathrm{R} \$) \\
\text { Diet cost/kg } L W(R \$)\end{array}$ & 0,49 & 0,48 & 0,45 & 0,46 \\
\hline $\begin{array}{l}\text { Receita bruta }(\mathrm{R} \$) \\
\text { Total income }(R S)\end{array}$ & 1,63 & 1,58 & 1,55 & 1,60 \\
\hline $\begin{array}{l}\text { Receita líquida }(\mathrm{R} \$)^{1} \\
\text { Net income }(R \$)\end{array}$ & 0,50 & 0,52 & 0,57 & 0,56 \\
\hline $\begin{array}{l}\text { Peso da aarcaça eviscerada (g) } \\
\text { Carcass weight }(g)\end{array}$ & 1,76 & 1,72 & 1,70 & 1,71 \\
\hline $\begin{array}{l}\text { Preço do } \mathrm{kg} \text { da carcaça }(\mathrm{R} \$) \\
\text { Carcass price }(R \$ / \mathrm{kg})\end{array}$ & 1,35 & 1,35 & 1,35 & 1,35 \\
\hline $\begin{array}{l}\text { Custo de ração/kg de carcaça }(\mathrm{R} \$) \\
\text { Diet cost/kg carcass }(R \$)\end{array}$ & 0,64 & 0,62 & 0,58 & 0,61 \\
\hline $\begin{array}{l}\text { Receita bruta }(\mathrm{R} \$) \\
\text { Total income }(R S)\end{array}$ & 2,38 & 2,32 & 2,30 & 2,31 \\
\hline $\begin{array}{l}\text { Receita líquida }(\mathrm{R} \$)^{1} \\
\text { Net income }(R S)\end{array}$ & 1,25 & 1,26 & 1,32 & 1,27 \\
\hline
\end{tabular}

${ }^{1}$ Receita líquida = Receita bruta - despesa com ração (Net income = total income - feed cost). 
a relação energia:proteína das dietas do PN2 (145,2; 165,8 e 181,2). Contudo, as relações do plano PN4 $(146,21 ; 167,5$ e 188,8$)$ e PN3 $(147,3 ; 167,0$ e 187,0$)$ foram superiores ao do plano PN2. O coeficiente de variação da \% de gordura abdominal foi superior as outras medidas de carcaça, o que é normal nesse tipo de variável, esse fato pode ter interferido na análise estatística deste parâmetro. Resultados mais coerentes foram observados por MacLeod (1991), onde a gordura abdominal reduziu quando a relação energia:proteína decresceu, já que menores relações possuem maiores níveis de proteína. Waldroup et al. (1990) e Deschepper \& De Groote (1995) relatam que o aumento do nível de aminoácidos e proteína da dieta resultam em redução da gordura abdominal das carcaças. Leeson (1995) cita que o aumento do nível energético da dieta pode resultar em maior percentagem de gordura na carcaça, enquanto o aumento do conteúdo de proteína da dieta , reduz a percentagem de gordura, com pouca alteração de carne de peito depositada.

Tabela 9 - Receita obtida com a comercialização do frango em cortes (machos), alimentados com diferentes planos nutricionais

Table 9 - Income obtained with commercialization of broilers (male) under different feeding program

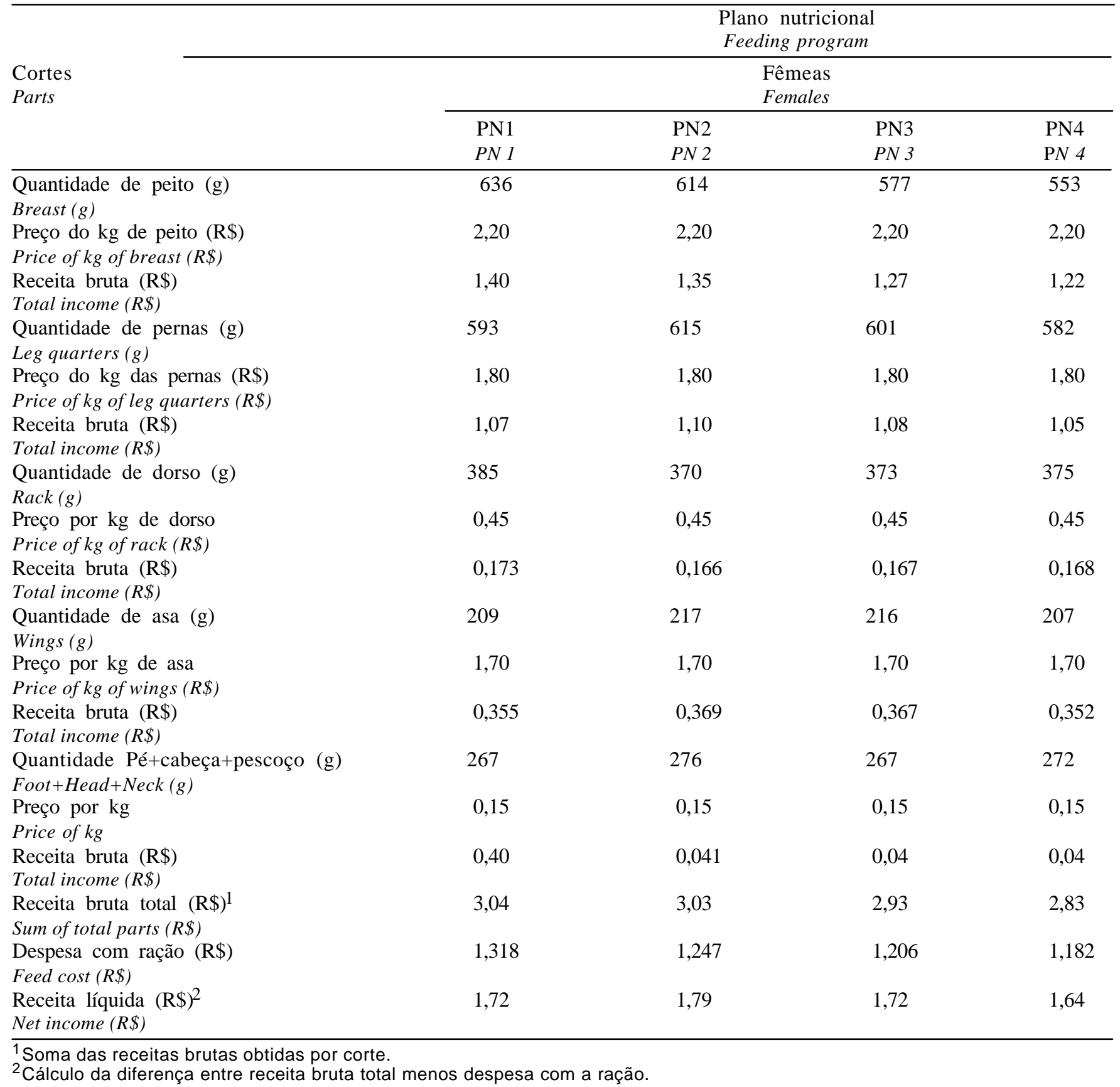


Tabela 10 - Receita obtida com a comercialização do frango em cortes (fêmeas), alimentados com diferentes planos nutricionais

Table 10 - Income obtained with commercialization of broilers (female) fed with different nutritional plan

\begin{tabular}{|c|c|c|c|c|}
\hline \multirow{3}{*}{$\begin{array}{l}\text { Cortes } \\
\text { Parts }\end{array}$} & \multicolumn{4}{|c|}{$\begin{array}{l}\text { Plano nutricional } \\
\text { Nutritional plan }\end{array}$} \\
\hline & \multicolumn{4}{|c|}{$\begin{array}{l}\text { Fêmeas } \\
\text { Female }\end{array}$} \\
\hline & PN1 & PN2 & PN3 & PN4 \\
\hline $\begin{array}{l}\text { Quantidade de peito }(\mathrm{g}) \\
\text { Breast }(\mathrm{g})\end{array}$ & 540 & 500 & 520 & 510 \\
\hline $\begin{array}{l}\text { Preço do } \mathrm{kg} \text { de peito }(\mathrm{R} \$) \\
\text { Price of } \mathrm{kg} \text { of breast }(R \$)\end{array}$ & 2,20 & 2,20 & 2,20 & 2,20 \\
\hline $\begin{array}{l}\text { Receita bruta }(\mathrm{R} \$) \\
\text { Total Income }(R \$)\end{array}$ & 1,19 & 1,10 & 1,14 & 1,12 \\
\hline $\begin{array}{l}\text { Quantidade de pernas (g) } \\
\text { Leg quarters }(g)\end{array}$ & 0,48 & 0,47 & 0,46 & 0,45 \\
\hline $\begin{array}{l}\text { Preço do } \mathrm{kg} \text { das pernas }(\mathrm{R} \$) \\
\text { Price of } k g \text { of leg quarters }(R \$)\end{array}$ & 1,80 & 1,80 & 1,80 & 1,80 \\
\hline $\begin{array}{l}\text { Receita bruta }(\mathrm{R} \$) \\
\text { Total income }(R \$)\end{array}$ & 0,86 & 0,85 & 0,83 & 0,81 \\
\hline $\begin{array}{l}\text { Quantidade de dorso (g) } \\
\text { Rack }(g)\end{array}$ & 0,31 & 0,31 & 0,31 & 0,31 \\
\hline $\begin{array}{l}\text { Preço por } \mathrm{kg} \text { de dorso } \\
\text { Price of } k g \text { of rack }(R \$)\end{array}$ & 0,45 & 0,45 & 0,45 & 0,45 \\
\hline $\begin{array}{l}\text { Receita bruta }(\mathrm{R} \$) \\
\text { Total income }(R \$)\end{array}$ & 0,14 & 0,14 & 0,14 & 0,14 \\
\hline $\begin{array}{l}\text { Quantidade de asa (g) } \\
\text { Wings }(g)\end{array}$ & 0,209 & 0,217 & 0,216 & 0,207 \\
\hline $\begin{array}{l}\text { Preço por } \mathrm{kg} \text { de asa } \\
\text { Price of } k g \text { of wings }(R \$)\end{array}$ & 1,70 & 1,70 & 1,70 & 1,70 \\
\hline $\begin{array}{l}\text { Receita bruta }(\mathrm{R} \$) \\
\text { Total income }(R \$)\end{array}$ & 0,29 & 0,31 & 0,29 & 0,31 \\
\hline $\begin{array}{l}\text { Quantidade Pé+cabeça+pescoço (g) } \\
\text { Foot+Head+Neck }(g)\end{array}$ & 0,170 & 0,180 & 0,200 & 0,200 \\
\hline $\begin{array}{l}\text { Preço por } \mathrm{kg} \\
\text { Price of } \mathrm{kg}\end{array}$ & 0,15 & 0,15 & 0,15 & 0,15 \\
\hline $\begin{array}{l}\text { Receita bruta }(\mathrm{R} \$) \\
\text { Total Income }(R \$)\end{array}$ & 0,03 & 0,03 & 0,03 & 0,0 \\
\hline $\begin{array}{l}\text { Receita bruta total }(\mathrm{R} \$)^{1} \\
\text { Sum of total parts }(R \$)\end{array}$ & 2,51 & 2,42 & 2,43 & 2,41 \\
\hline $\begin{array}{l}\text { Despesa com ração }(\mathrm{R} \$) \\
\text { Feed cost }(R \$)\end{array}$ & 1,13 & 1,06 & 0,98 & 1,04 \\
\hline $\begin{array}{l}\text { Receita líquida }(\mathrm{R} \$)^{2} \\
\text { Net income }(R \$)\end{array}$ & 1,38 & 1,36 & 1,45 & 1,37 \\
\hline
\end{tabular}

1 Soma das Receitas brutas obtidas por corte.

${ }^{2}$ Calculo da diferença entre receita bruta total menos despesa com a ração.

Na Tabela 8, está apresentado um estudo da viabilidade econômica dos diferentes planos nutricionais com relação aos produtos comerciais (peso vivo e carcaça). Observa-se que os resultados foram diferentes em função dos produtos comercializados e do sexo. Para os machos o plano PN3 mostrou-se mais eficiente economicamente quando o frango foi vendido em peso vivo, já que houve maior receita entre o valor do frango e o custo da ração. No entanto, quando comercializado como carcaça eviscerada (com pé, pescoço e cabeça) o plano mais viável foi o
PN2. Esses dados concordam com outros trabalhos onde verificaram que o menor custo por $\mathrm{kg}$ de frango vivo foi obtido com plano nutricional com teores energéticos mais baixos (Bertechini et al.,1991b) e com níveis intermediários de energia nas rações (Bernal \& Baião, 1996). Para as fêmeas o plano PN3 foi o que apresentou maior retorno econômico, quando foram comercializadas em peso vivo ou em carcaça.

Quando o frango foi comercializado em partes (Tabelas 9 e 10), a maior receita foi obtida com o plano PN2 para machos e de PN3 para fêmeas. 


\section{Conclusões}

Os níveis de energia metabolizável e proteína bruta dos diferentes planos nutricionais influenciaram o ganho de peso e a conversão alimentar dos machos e fêmeas, e o rendimento de peito em machos.

Os frangos machos respondem com maior retorno econômico o aumento do plano nutricional das rações, enquanto as fêmeas respondem com limitações.

\section{Agradecimento}

Em especial, à empresa São Salvador (Itaberaí, GO), pelo apoio para realização deste trabalho de pesquisa.

\section{Literatura Citada}

BARBOSA, M.J.B.; CAMPOS, E.J. Energia metabolizável nas rações e desempenho sobre o desempenho de frangos de corte criados com separação de sexo. Arquivo Brasileiro de Medicina Veterinária, v.46, n.4, p.398-408, 1994.

BASTOS, E.C.G.;LANA, G.R.Q.; SILVA, R.G.C. Efeitos de níveis de energia da dieta e do sexo sobre o desempenho produtivo e rendimento de cortes nobres em frangos de corte. In: REUNIÃO ANUAL DA SOCIEDADE BRASILEIRA DEZOOTECNIA, 35., 1998, Botucatu. Anais... Botucatu: Sociedade Brasileira de Zootecnia, 1998. p.466-67.

BERNAL, F.E.M.; BAIÃO, N.C. Efeito dos níveis de energia da ração sobre o desempenho e o teor de gordura na carcaça de frangos de corte. Arquivo Brasileiro de Medicina Veterinária, v.48, n.5, p.595-606, 1996.

BERTECHINI, A.G.; ROSTAGNO, H.S.; SOARES, P.R. et al. Efeitos da variação do nível de energia nas rações inicial e final sobre o desempenho e carcaça de frangos de corte. Revista da Sociedade Brasileira de Zootecnia, v.20, n.3,p.241-249, 1991a.

BERTECHINI, A.G.; ROSTAGNO, H.S.; SOARES, P.R. et al. Efeitos de programas de alimentação e níveis de energia da ração sobre o desempenho e a carcaça de frangos de corte. Revista da Sociedade Brasileira de Zootecnia, v.20, n.3, p.267-80, 1991b.

CASTRO, A.J.; GOMES, P.C.; PUPA, J.M.R. et al. Exigência de triptofano para frangos de corte, de 43 a 49 dias de idade. In: CONFERÊNCIA APINCO DE CIÊNCIA E TECNOLOGIA AVÍCOLAS, 1998, Curitiba.Anais...Campinas: FACTA, 1998. p.22.

CELLA, P.S., DONZELE, J.L., OLIVEIRA, R.F.M. et al. Planos de nutrição para frangos de corte no período de 1 a 49 dias de idade mantidos em condições de conforto térmico. Revista Brasileira de Zootecnia, v.30, n.2, p.425-432, 2001.

DESCHEPPER, K., GROOTE, G. Effects of dietary protein, essential and non-essential amino acids on the performance and carcass composition of male broiler chickens. British Poultry Science, v.36, n.3, p 229-45, 1995.

JUNQUEIRA, O.M.; ARAÚJO, L.F.; FARIA, D.E. Energia para frangos de corte. In: SIMPÓSIO INTERNACIONAL SOBRE NUTRIÇÃO DE AVES, 1999, Campinas. Anais... Campinas: FACTA, 1999. p.41-52.

KIDD, M.T., KERR, B.J., HALPIN, K.M. et al. Lysine levels in starter and grower-finisher diets affect broiler perfomance and carcass traits. Journal of Applied Poultry Research, v.7, p.351-58, 1998.

LANA, G.R.Q.; SILVA JR., R.G.C.; VALERIO, S.R. et al. Efeito da densidade e do programa de alimentação sobre o desempenho de frango de corte. Revista Brasileira de Zootecnia, v.30, n.4, p.1258-1265, 2001.

LEESON, S. Nutrição e qualidade da carcaça de frangos de corte. In: CONFERÊNCIA APINCO DE CIÊNCIA E TECNOLOGIA AVÍCOLAS, 1995. Curitiba. Anais...Campinas: FACTA, 1995. p.111-18.

LEESON, S.; CASTON, L.; SUMMERS, J.D. Broiler response to diet energy. Poultry Science, v.75, p.529-535, 1996.

MACLEOD, M.G. Fat deposition and heat production as responses to surplus dietary energy in folws given a wide range os metabolizables energy: protein ratios. British Poultry Science, v.32, p.1097-1108, 1991.

NASCIMENTO, A.H.; ALBINO, L.F.T.; POZZA, P.C. et al. Energia e relação energia:proteína na fase inicial de frangos de corte. In: CONFERÊNCIA APINCO DE CIÊNCIA E TECNOLOGIA AVÍCOLAS, 1998, Campinas. Anais... Campinas: FACTA, 1998. p.15.

NATIONAL RESEARCH COUNCIL - NRC. Nutrient requirements of poultry. Washington, D.C.: University Press, 1994. $155 \mathrm{p}$.

PEAK, S.D.; WALSH, T.J.; BENTON, C.E. et al. Effects of two planes of nutrition on performance and uniformity of four strains of broiler chicks. Applied Poultry Research, v.9, n.2, p.185-194, 2000.

PESTI, G.M. Proteínas (aminoácidos) para frangos.In: SIMPÓSIO INTERNACIONAL SOBRE NUTRIÇÃO DE AVES, 1999. Campinas. Anais...Campinas: FACTA, 1999. p.97-110.

SILVA, J.H.V.; ALBINO, L.F.T .; NASCIMENTO, A.H. Níveis de energia e relações energia:proteína para frango de corte de 22 a 42 dias de idade. Revista Brasileira de Zootecnia, v.30, n.6, p.1791-1800, 2001.

SILVA, P.C.; ROSTAGNO, H.S.; FONSECA, J.B. et al. Níveis de proteína e aminoácidos para frangos de corte na fase de acabamento. In: REUNIÃO DA SOCIEDADE BRASILEIRA DE ZOOTECNIA, 34., 1997, Juiz de Fora. Anais... Juiz de Fora: Sociedade Brasileira de Zootecnia, 1997. p.173.

STRINGHINI, J.H. Níveis de proteína e aminoácidos em rações para frangos de corte criados em duas densidades populacionais. Jaboticabal: Universidade Estadual Paulista, 1998. 117p. Tese (Doutorado em Produção Animal) - Universidade Estadual Paulista, 1998.

SUMMERS, J.D.; LEESON, S.. Influence of dietary protein and energy level on broiler performance and carcass composition. Nutrition Reports International, v.29, n.4, p.757-67, 1984.

UNIVERSIDADE FEDERAL DE VIÇOSA - UFV. SAEG (Sistema de Análise Estatística e Genética), Versão 71,Viçosa, MG: 1997.104p.

WALDROUP, P.W. Nutrient requirements of broilers. In: INTERNATIONAL SYMPOSIUM ON NUTRITIONAL REQUIREMENTS OF POULTRY AND SWINE, 1996, Viçosa, MG. Anais... Viçosa, MG: Universidade Federal de Viçosa, 1996. p.55-63.

WALDROUP, P.W.; TIDWELL, N.M.; IZAT, A.L. The effects of energy and amino acids levels on performance and carcass quality of male and female broilers grown separately. Poultry Science, v.69, p.1513-1521, 1990.

Recebido em:03/06/02 Aceito em: 29/10/02

R. Bras. Zootec., v.32, n.3, p.620-631, 2003 